\title{
Ethanol enhances the psychostimulant effect and the monoamine release induced by mephedrone in rats
}

\author{
Jordi Camarasa ${ }^{1}$, Raul Lopez-Arnau ${ }^{1}$, Mario Buenrostro-Jauregui ${ }^{2}$, Elena Escubedo ${ }^{1}$, David Pubill ${ }^{1}$ \\ ${ }^{1}$ Pharmacology, Toxicology and Therapeutic Chemistry, University of Barcelona, Spain, ${ }^{2}$ Neuroscience Laboratory, \\ Department of Psychology, Universidad Iberoamericana, Ciudad de Mexico, Mexico
}

Background: Mephedrone (4-methylmethcathinone) is an increasingly consumed synthetic cathinone with powerful psychostimulant effects. Previous studies in rodents have also shown that ethanol (EtOH), a drug which is the most combined with mephedrone, potentiates the psychostimulant effects of MDMA (3,4,-methylenedioxymethamphetamine). Given the similarities between MDMA and mephedrone's mechanism of action, a similar profile should be expected when combined with EtOH. Therefore, the aim of the present study was to assess the effects of the combination of mephedrone plus $\mathrm{EtOH}$ on dopamine (DA) and serotonin (5-HT) release in the nucleus accumbens (NAc) and the medial prefrontal cortex (mPFC) as well as on locomotor activity.

Methods: A microdialysis probe was stereotaxically inserted into either the NAc or the mPFC of male Sprague-Dawley rats. 7 days after, animals were administered with saline, $\mathrm{EtOH}(1 \mathrm{~g} / \mathrm{kg}$, i.p.), mephedrone $(25 \mathrm{mg} / \mathrm{kg}$, s.c.) or EtOH plus mephedrone. 5-HT and DA content as well as their major metabolites (5-hydroxyindolacetic acid and 3,4dihydroxyphenylacetic acid) were determined by HPLC-MS. Moreover, the locomotor activity was also registered.

Results: EtOH potentiated 5-HT release compared with mephedrone alone ( $85 \%$ in NAc and 65\% in $\mathrm{mPFC}$ ). The increased release of 5-HT lasted longer $(120 \mathrm{~min})$ in $\mathrm{mPFC}$ after administration of mephedrone plus EtOH than after mephedrone alone $(60 \mathrm{~min})$. A potentiation of DA release was only observed in the NAc at 60 min post-administration. Mephedrone reduced the 5-HT and DA metabolism. EtOH did not modify the 5-HT and DA metabolic profile induced by mephedrone. EtOH increased the psychostimulant effect induced by mephedrone (Total distance: mephedrone = $20419 \pm 4126 \mathrm{~cm}, \mathrm{EtOH}+$ mephedrone $=33472 \pm 3402 \mathrm{~cm} ; \mathrm{p}<0.01)$.

Conclusion: We demonstrate a potentiation of the increase in monoamines release and in the psychostimulant effect when combining mephedrone plus EtOH, which might also involve an increased abuse liability of this new drug of abuse. Funding: SAF2016-75347-R and PNSD 20161004. 